\title{
KEAN - a arte do ator vista pelo romantismo
}

Claudia M. Braga*

O final do século XVIII assiste a profundas alterações políticas e sociais por toda a Europa, ocasionadas em grande parte em conseqüência do movimento anti-monarquista ocorrido na França, que tem seu ápice em 1789 e continua a reverberar pelo país e pelo continente ao longo de todo o século XIX.

Estas alterações, que marcarão o fim de uma época, sobretudo no que se refere à organização social, são, por sua vez, resultado de transformações do próprio pensamento europeu que redundarão, em termos de expressão artística, num movimento de reação radical às regras neoclássicas em todas as formas de arte, entre elas o teatro.

\section{Hugo e o prefácio de Cromwell}

Malgrado sua existência nos palcos ser manifesta desde antes desta data, é apenas em 1830 que o movimento romântico será objeto de um texto que buscará estabelecer suas bases teóricas. Este texto, verdadeiro manifesto dos anseios da nova geração de autores que se lançava nas letras, aparecerá como prefácio do drama Cromwell - ele próprio inexpressivo em termos teatrais - de Victor Hugo.

Considerando-se pois que, na realidade, as propostas estéticas apresentadas pelo "Prefácio" já estavam sendo levadas a efeito desde antes de seu aparecimento - nos melodramas, por exemplo, ou mesmo em peças já classificadas como românticas, como o Henri III, de Alexandre Dumas, que estreara em 1829 - sua importância deve-se mais à posição ocupada por seu autor entre os novos poetas e ao fato de terem sido tais propostas ali sistematizadas que às "novidades" que continham.

E o que propunha o Prefácio de Cromwell?

Basicamente, em primeiro lugar, o fim da divisão entre os gêneros, apoia-

* Claudia M. Braga é professora Adjunta da UFSJ São João del-Rei (MG) 
do no pressuposto de que, na vida, o belo e o grotesco se entrecruzavam e se superpunham, formando um todo contínuo. Nesse sentido, segundo Hugo,

(...) a musa moderna verá as coisas com um olhar mais elevado e mais amplo. Sentirá que tudo na criação não é humanamente belo, que o feio existe ao lado do belo, o disforme perto do gracioso, o grotesco no reverso do sublime, o mal com o bem, a sombra com a luz. (1988: 25)

Mais ainda, Hugo estabelecia a noção do gênio, do talento artístico, e é esta a questão que aqui nos interessará sobremaneira.

\section{Um novo conceito de "artista"}

Até o século XIX o artista era, de modo geral, alguém que expressava a sociedade, fosse ele ator, pintor ou autor, teatral ou não. Sobre estes últimos, observa Harnold Hauser:

Até o século XVIII, os autores nunca haviam sido outra coisa senão os porta-vozes do seu público; cuidavam dos seus leitores, assim como os criados e empregados tratavam dos seus bens materiais. Aceitavam e confirmavam os princípios morais e os critérios de gosto geralmente reconhecidos, não os inventavam nem os alteravam (...) É só no século XVIII que o público se separa em dois campos diferentes, e a arte em duas tendências rivais. Daí por diante, cada artista é confrontado por uma dualidade de ordens opostas: o mundo da aristocracia conservadora e o da burguesia progressiva, entre um grupo que se agarra obstinadamente aos velhos valores, tradicionais e supostamente absolutos, e outro que se baseia no ponto de vista de que mesmo esses valores, e eles mais do que nada, são historicamente condicionados, e que outros, mais recentes, estão mais de acordo com o bem geral. (1982:884)

A transformação trazida pelo surgimento desta divisão entre conservadores e progressistas obrigará o artista a tomadas de posições antes inimagináveis mas que serão todavia efetuadas e, no desenrolar dos embates ocorridos, findarão por afastá-lo dos vitoriosos burgueses de 1789, sobretudo após os eventos conhecidos como os Três Gloriosos (julho de 1830), que depõem mais uma vez um Bourbon do trono francês e contam com ativa participação dos artistas das letras. Assim, depois de 1830, ainda segundo Hauser, "a burguesia passa a suspeitar do artista, e prefere à aliança de até 
então, a neutralidade. A Revue des Deux Mondes opina agora que não é necessário, mas efetivamente indesejável, que o artista tenha idéias políticas e sociais próprias" (1982:899).

Dessa forma, é efetivamente a partir do século XIX que o artista ganharia um status diferenciado com relação ao grupo social, passando a ser aureolado com o conceito do "talento", do "gênio", o que o libertaria das regras comportamentais e o colocaria, digamos assim, à margem das normas sociais estabelecidas.

Este é também o pensamento que aparece no prefácio, no qual o artista descrito Hugo será aquele que

é uma árvore que pode ser açoitada por todos os ventos e irrigada por todos os orvalhos, que traz suas obras como seus frutos, da mesma forma que o fabuleiro trazia suas fábulas. Para que prender-se a um mestre? Enxertar-se com um modelo? Vale mais ainda ser o espinheiro ou cardo, alimentado com a mesma terra que o cedro e a palmeira, que ser o fungo ou o líquen destas grandes árvores. (1988:59) e, com efeito, é desse modo que começaram a se ver a si próprios os artistas de modo geral, numa atitude de diferenciação facilmente reconhecível mesmo nos dias de hoje.

Se o conceito se arraiga e mantém-se colado à imagem do artista até a atualidade, é todavia no século XIX - no período romântico em especial - que ele será mais amplamente discutido e vivenciado, tendo sido objeto, no caso específico dos atores, de mais de um "tratado" ou "manual" de interpretação, escrito pelos próprios atores, e ainda, como se verá adiante, de pelo menos um drama de grande sucesso.

\section{A arte de representar e o século XIX}

No embalo das propostas românticas, da noção de gênio ali inseridas, a função do ator tomara outra dimensão ao longo do século, passando a ser definida, entre todas as profissões artísticas, como aquela que mais necessita da liberdade, da "experiência" vívida da emoção para se realizar plenamente. Este ponto de vista, que exclui entretanto os atores cômicos, se manifestará de diferentes formas. Alexandre Dumas, por exemplo, definirá explicitamente as diferenças entre a representação de comédias e de dramas e, assim, as diferentes exigências feitas aos atores de cada um dos gêneros.

A comédia é a pintura de costumes e o drama é a das paixões; 
a comédia é a sociedade, o drama é a humanidade. A sociedade muda, cada século lhe dá uma nova face. A humanidade é invariável, suas paixões são idênticas; elas se manifestam da mesma maneira no teatro hindu, no teatro grego, no teatro romano, no teatro inglês, no teatro alemão e no teatro francês. O ator chamado a representar a comédia deve então ter "visto". O ator chamado a representar o drama só necessita de ter "experimentado". (DUMAS, 1867:V - tradução nossa)

No mesmo sentido, alguns atores, como Riccoboni (1707-1772), Aristippe (1800?-1864?) e o brasileiro João Caetano (1808-1863), se dedicarão a registrar para a posteridade suas técnicas e estratégias de representação, que enfatizavam, de modo geral, a excessiva emoção de que eram presos esses profissionais e a conseqüente necessidade de um constante autocontrole no ato da representação.

Como exemplo deste tipo de posicionamento, poderíamos citar as Lições Dramáticas, de João Caetano - que exprimem não apenas o ponto de vista deste ator sobre a arte de representar mas também o de François Riccoboni, cujo L'art du théâtre é a mais clara fonte dos escritos do ator brasileiro - que afirma em seu manual que "o ator imita, e não iguala a natureza. O seu jogo é todo de convenção, criando, por assim dizer, uma segunda natureza para si, comovendo-se, arrebatando-se e exasperando-se até o ponto que Ihe convém" (PRADO, 1984:27). Vale dizer que esta mesma convenção mencionada pelo ator, ele próprio terá, por sinal, certa dificuldade em seguir, a se considerar os comentários gerais a respeito de sua extrema entrega às emoções dos personagens, quando no palco.

\section{O ator romântico}

Entre os artistas da cena no período, alguns chamaram a atenção sobre suas formas de atuar, angariando tanto a admiração de seu público quanto os comentários - nem sempre elogiosos - da crítica, a respeito de sua arte. No Brasil, João Caetano dos Santos dominou os palcos da capital (o Rio de Janeiro, à época), desde sua estréia, em 1838, até aproximadamente 1860 quando, além de bastante perseguido pelos jovens intelectuais ligados à corrente realista, adoece gravemente, o que o impede definitivamente de voltar aos palcos.

Com um talento talhado para o romantismo, João Caetano buscaria entretanto um modelo de interpretação neoclássico: o francês Talma, conhecido ator trágico. O brasileiro se aproximaria mais, todavia, da forma interpretativa de Frédéric Lemaître, ator romântico celebrizado por sua atuação como Ro- 
bert Macaire, em L'Auberge des Adrets (1823).

Menos admirado, mas também conhecido do brasileiro Santos e bastante famoso na Europa e na América do Norte - em cujos palcos se apresentou de 1820 a 1821 - é o ator inglês Edmond Kean (1787?-1833) quem melhor encarna o espírito do tempo, tanto na forma de representação apaixonada quanto na assimilação do conceito de marginalização social em que passa a ser colocado o artista.

Um tanto tumultuada pelos excessos a que se entregava, a vida pessoal de Edmond Kean chamou tanta atenção quanto sua carreira artística. Se seu talento na interpretação - dedicado expressivamente aos grandes personagens shakespeareanos - consagrou-se a partir de sua representação do Shylock, no Mercador de Veneza (1814), suas aventuras (ou desventuras) amorosas obrigaram-no, por exemplo, a deixar a Inglaterra em 1820. No período em que trabalhou nos palcos norte-americanos, construiu também aí uma sólida reputação. Sua saída do país deveu-se, entretanto, a mais uma complicação causada por seu intempestivo caráter: a quebra de um contrato de representações em Boston inviabilizou a continuidade de sua carreira norte-americana.

A entrega total deste ator às paixões e à arte transformou-o, de certa forma, no protótipo do ator romântico, guindando-o à categoria de personagem, como se observa em Kean ou désordre et génie, drama de Alexandre Dumas inúmeras vezes transformado em filme - sendo a primeira filmagem de 1923 e a última, por nós conhecida, de 1988, com Jean-Paul Belmondo no papel principal - e reescrito por Jean-Paul Sartre no século XX.

\section{Kean - a desordem que explicaria o gênio}

A peça de Dumas, em sua busca de recriar no registro romântico o quasepersonagem que teria sido o atorEdmond Kean, traça, neste percurso, um perfil da "grande sociedade" do século e de suas posições sobre o artista em geral.

Logo ao abrir-se o pano, numa conversa entre as condessas de Kœfeld e Gosswill, fica estabelecida a situação do ator nesta sociedade. Perturbada pelos comentários maliciosos da segunda a respeito de um possível amor por Kean, a condessa de Kœfeld pergunta à companheira porque não se poderia amá-lo. A resposta não deixa dúvidas sobre qual seria o ponto de vista geral sobre os atores:

Amy - (...) d'abord, parce que c'est un comédien, et que, ces sortes de gens n'étant pas reçus dans nos salons... 
(...) Kean est un véritable héros de débauche et de scandale ! un homme qui se pique d'effacer Lovelace par la multiplicité de ses amours, qui lutte le luxe avec le prince royal, et qui, avec tout cela, par un contraste qui dénonce son extraction, revêt, à peine débarrassé du manteau de Richard, l'habit d'un matelot du port, court de taverne en taverne, et se fait rapporter chez lui plus souvent qu'il n'y rentre.

\section{(...)}

Un homme criblé de dettes, qui spécule, dit-on, sur les caprices de certaines grandes dames pour échapper aux poursuites de ses créanciers. (Acte I, scène II)

Nesta altura entra em cena o conde de Kœfeld, informando haver convidado o maior ator da Inglaterra para o jantar. O fato causa certo escândalo entre as damas e a explicação do conde acaba por estabelecer a distinção entre as pessoas "de bem" e os artistas:

Le comte - Pourquoi pas ? Le prince royal l'invite bien ! D'ailleurs, inviter, inviter comme on invite ces messieurs, en qualité de bouffon : nous lui ferons jouer une scène de Falstaff après le dîner... Cela nous amusera, nous rirons. (Acte I, scène III)

Feitas as apresentações, o drama se desenvolve no embate entre este "olhar" assimilado pela voz geral e a figura de Kean que transita diante dele. Nesse conflito, embora o ator seja sempre pintado com as tintas da nobreza de caráter e da lealdade, tampouco a intimidade do ator mostrada por Dumas desmentirá - muito pelo contrário, aliás - a fama de desregramentos que o artista carrega. A rubrica de abertura do $2^{\circ}$ ato traça um quadro nada edificante de seus momentos fora do palco:

Un salon chez Kean. Au lever du rideau, le théâtre présente toutes les traces d'une orgie. Kean dort sur une table, tenant d'une mais le tuyau d'une pipe turque, et de l'autre le goulot d'une bouteille de rhum. David est étendu sous la table. Tom est couché. Bardolph est à cheval sur une chaise. Des bouteilles vides ont roulé à terre ; deux ou trois, à moitié pleines, son restées sur la table. (...)

Este "gênio em desordem" tem em Salomon, seu ponto, uma espécie de anjo da guarda que tenta poupar-lhe os vexames públicos e, ao chegar para acordá-lo, expulsa os companheiros de orgia. Nem Salomon, entretanto, deixa de tecer para si próprio comentários sobre o mestre... 
Salomon - (...) C'est la sixième fois depuis le commencement du mois, et nous sommes aujourd'hui le 7 ! Et avec qui encore fait-il de pareilles orgies ? Avec de misérables cabotins qui jouent le Lion... la Muraille... (...) Vraiment, si on les trouvait ici, je serais bien honteux pour l'illustre Kean... (...)

Quand je pense que j'ai là, devant les yeux, couché comme un boxeur éreinté, le noble, l'illustre, le sublime Kean, l'ami du prince de Galles !... le roi des tragédiens passés, présents et futurs... qui tient en ce moment le sceptre... (II aperçoit la bouteille que Kean tient par le goulot.) Quand je dis sceptre, je me trompe... Oh ! mon Dieu ! (Acte II, scène I)

E a justificativa apresentada pelo ator para os excessos recriminados por seu subalterno inicia a versão do artista para seu modo de vida.

Kean - Tu as raison, mon vieil ami, tu as raison ; je sens que je me tue avec cette vie de débauches et d'orgies ! Mais, que veuxtu ! je ne puis en changer ! II faut qu'un acteur connaisse toutes les passions pour les bien exprimer. Je les étudie sur moi-même, c'est le moyen de les savoir par cœur. (Acte II, scène II)

Ao longo da peça Dumas completa o perfil de seu herói, talhado com o cinzel do contraste: se suas origens são humildes, tendo iniciado a carreira como saltimbanco, sua alma é mais nobre que a dos nobres com os quais é comparado; ainda que se entregue ao álcool, seu caráter o exime das culpas maiores que daí poderiam decorrer; mesmo seu comportamento para com as mulheres apresentado no drama desmente as afirmações inicialmente prestadas sobre ele.

Observa-se, então, que no próprio ator é aplicada a "teoria dos opostos" proposta pelo romantismo. O retrato de Kean ali pintado é em si o que de melhor se poderia esperar como comprovação de que num só espaço, num só homem, convivem lado a lado o grotesco e o sublime.

Quanto à relação do ator com a sociedade, Dumas a mostra sempre ambivalente, sendo ele ao mesmo tempo respeitado e amado por sua genialidade em cena e repudiado por suas origens e sua profissão.

Neste sentido, se na comparação com o Príncipe de Galles ou com o conde de Kœfeld Kean é visto como igual em estatura moral e nobreza, num confronto com lord Mewill, um nobre devasso e empobrecido por uma vida de jogos, que se recusara a um duelo com o ator, Dumas eleva seu protagonista a um status muito maior que o de seu adversário, traçando um 
quadro comparativo extremamente depreciativo para o par da Inglaterra, o que possivelmente traduz, também, o declínio da autoridade nobiliárquica característico do século:

Kean, reposant à terre une chaise qu'il avait soulevée - Oui, vous avez raison, il y a trop de distance entre nous. Lord Mewill est un homme honorable, tenant à une des premières familles d'Angleterre... de riche et veille noblesse conquérante... si je ne me trompe. Il est vrai que lord Mewill a mangé la fortune de ses pères en j e u x de cartes et de dés, en paris de coqs et en courses de chevaux; il est vrai que son blason est terni de la vapeur de sa vie débauchée, et de ses basses actions... et qu'au lieu de monter encore, il a descendu toujours. Tandis que le bateleur Kean est né sur le grabat du peuple, a été exposé sur la place publique, et, ayant commencé sans nom et sans fortune, s'est fait un nom égal au plus noble nom, et une fortune qui, du jour où il voudra bien, peut rivaliser avec celle du prince royal... Cela n'empêche pas que lord Mewill ne soit un homme honorable, et Kean un saltimbanque ! - II est vrai que lord Mewill a voulu rétablir sa fortune au détriment de celle d'une jeune fille belle et sans défense ; que sans faire attention qu'elle était d'une classe au-dessous de la sienne, il l'a fatiguée de son amour, poursuivie de ses prétentions, écrasée de son influence. Tandis que le saltimbanque Kean a offert protection à la fugitive, qui est venue la lui demander, qu'il l'a reçue chez lui comme un frère aurait reçu une sœur, et qu'il l'en a laissée sortir pure, ainsi qu'elle y était entrée... quoiqu'elle fût belle, jeune et sans défense... Cela n'empêche pas que Mewill ne soit un lord, et Kean un saltimbanque !... II est vrai que lord Mewill, pair d'Angleterre, a son siège à la Chambre suprême, fait et défait les lois de notre vieille Angleterre, porte une couronne comtale sur sa voiture, et un manteau de pair sus ses épaules, et n'a qu'à dire son nom pour voir ouvrir devant lui la porte du palais de nos rois... Cela fait que parfois lord Mewill, lorsqu'il daigne descendre parmi le peuple, change de nom, soit qu'il rougisse de celui de ses aïeux, soit qu'il ne veuille pas les faire rougir... Alors il prend celui d'un bateleur et d'un saltimbanque et signe une lettre de ce faux nom... Ceci est une affaire de bagne et de galères... rien de plus... rien de moins... entendez-vous, milord ? Tandis que l'histrion Kean marche à visage découvert, lui ! et dit hautement son nom ; car le lustre de son nom ne lui vient pas de ses aïeux, mais y retourne $; \ldots$ tandis que l'histrion Kean arrache le masque à tout visage, au théâtre comme à la taverne, et fort de la loi qu'il a reçue, l'invoque contre celui qui l'a faite... Lorsque l'histrion Kean offre à lord Mewill 
de ne rien dire de tout cela, à la condition qu'il lui fera satisfaction d'une insulte, dont la société pourrait lui demander justice, lord Mewill répond qu'il ne peut pas se battre avec un bateleur, un saltimbanque, un histrion... Oh ! sur mon honneur ! c'est b i en répondu, car il y a trop de distance entre ces deux hommes. (...) (Acte III, scène XIV)

Ao mesmo tempo em que o eleva em estatura moral, Dumas o coloca, entretanto, como alguém que é prisioneiro de sua arte, que o sufoca e da qual não aufere lucros financeiros e que não lhe garantirá uma velhice confortável. A personagem chega a expressar essas opiniões a Salomon, que aventa a hipótese de o ator começar a ordenar melhor sua vida, o que provoca violenta reação de Kean, que justificará novamente, então, a necessidade do "gênio" em desordem para o florescimento do talento artístico, dizendo que se Deus lhe houvesse dado a honorável faculdade da ordem ele seria vendedor de tecidos e não ator.

E este gênio consagra-se inteiro a sua arte. No último ato, perturbado por fortes emoções pessoais o ator tenta recusar-se a representar, amaldiçoando a profissão que lhe obriga a fingir emoções que não são suas.

Kean - (...) Oh ! métier maudit... où aucune sensation ne nous appartient, où nous ne sommes maîtres ni de notre joue, ni de notre douleur... où, le cœur brisé, il faut jouer Falstaff ; où, le cœur joyeux, il faut jouer Hamlet ! toujours un masque, jamais un visage... Oui, oui, le public s'impatiente... car il m'attend pour s'amuser, et il ne sait pas qu'à cette heure, mes larmes m'étouffent. Oh ! quel supplice ! et puis, si j'entre en scène avec toutes les tortures de l'enfer dans le cœur ; si je ne souris pas là où il me faudra sourire, si ma pensée débordante change un mot de place, le public sifflera, le public, qui ne sait rien, qui ne comprend rien, qui ne devine rien de ce qui se passe derrière la toile... qui nous prend pour des automates... n'ayant d'autres passions que celles de nos rôles... Je ne jouerai pas. (Acte IV, scène VIII)

Ele vai para o palco, apesar dos protestos. Durante a representação, porém, tomado de fúria, insulta o herdeiro do trono inglês e o par da Inglaterra, sendo exilado do país. E se na vida real o ator faz carreira nos Estados Unidos durante seu período de exílio - interrompendo-a, novamente, em razão de seu intempestivo caráter - o drama, por sua vez, encerra-se no momento em que ele decide partir para a América do Norte, ao ser informado de seu banimento. 
Se não é o modelo de interpretação ideal, Kean representa, no entanto, o modelo do artista romântico tal como o viam o Hugo do "prefácio" e o próprio Dumas, trazendo em si e para a cena os contrastes propostos pelo movimento, a contraposição de sensações díspares, a desordem aliada e explicando o talento, sendo, tanto o homem real quanto a personagem, uma das mais expressivas representações da união do grotesco ao sublime.

\section{Bibliografia}

DUMAS, Alexandre. Drames romantiques. Paris, Omnibus, 2002.

DUMAS, Alexandre. Souvenirs dramatiques. Paris, 1867.

HAUSER, Arnold. História social da literatura e da arte, Tomo II.

Trad.: Walter Geenen. $3^{\mathrm{a}}$ ed. São Paulo: Ed. Mestre Jou, 1982.

HUGO, Victor. Do grotesco e do sublime (Prefácio de Cromwell).

Trad. Célia Berretini. São Paulo : Perspectiva, 1988.

PRADO, Décio de Almeida. João Caetano e a Arte do Ator. São Paulo : Ática, 1984. 